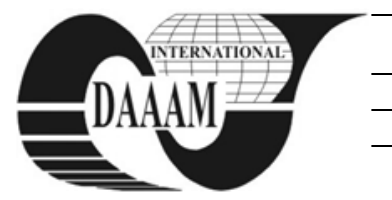

\title{
REFINEMENT OF TRIP STEEL MICROSTRUCTURE BY INCREMENTAL DEFORMATION
}

\author{
JIRKOVA, H[ana]; KUCEROVA, L[udmila]; MASEK, B[ohuslav] \& MEYER, L[othar] W[erner]
}

\begin{abstract}
TRIP steels represent a modern group of low alloyed steels offering a potential for excellent combination of strength and ductility. Unconventional forming methods employing the TRIP effect at final cold forming operation require not only very fine structure but also appropriate combination of phases in these steels. The microstructure development can be controlled by appropriate temperature interval and amount of incremental deformation. In this study, the influence of various temperature ranges and strain magnitudes in 20-step deformation schedule on grain refinement was investigated. Suitable parameters of the schedule led to ferrite-bainite microstructure with $15 \%$ retained austenite, ferrite grain size of about 2 um and elongation of about $30 \%$.
\end{abstract}

Key words: multiphase steel, TRIP steel, incremental deformation, thermomechanical treatment

\section{INTRODUCTION}

Low alloyed high strength steels represent new structural materials of recent decades. Upon appropriate heat or thermomechanical treatment, they can exhibit very good mechanical properties (Jirkova et al., 2009).

These materials include the group of TRIP steels. These are multiphase steels, whose microstructure consists of ferrite, bainite and a small amount of retained austenite (Bleck, 2002). They feature a good combination of strength and ductility provided by the TRIP effect based on the deformation induced martensitic transformation (Bleck, 2002). Thanks to their high capacity of energy absorption and good fatigue limit, they have recently been used in the automotive industry for making safety components ( $\mathrm{Li}$ et al., 2011). These include, for example, seat structures, cross-members, long post reinforcements, aprons and fender reinforcements.

The aim of this research was to investigate the influence of the deformation temperature interval and of the strain intensity on grain refinement and the microstructure structure for the purpose of a novel application.

\section{INFLUENCE OF DEFORMATION ON MICROSTRUCTURE DEVELOPMENT}

The influence of deformation on TRIP steels covers several aspects. It does not concern only the grain refinement but also the distribution and the final morphology of individual phases.

The deformation in the intercritical region from 730 to $800^{\circ} \mathrm{C}$ increases the volume fraction of ferrite by accelerating nucleation. When undeformed austenite transforms to ferrite, the nucleation is only possible on the grain boundaries. However, in case of transformation of deformed austenite, ferrite forms within the austenite grains, as well as on their boundaries (Basuki et al., 1999; Godet, 2004). Plastic deformation in the intercritical region speeds up the bainitic nucleation as well, but slows down its growth at the same time. Consequently, the bainite regions are smaller and the volume fraction of bainite decreases (Basuki et al., 1999; Godet, 2004). At the same time, it decreases the volume fraction of needlelike retained austenite. For this reason, higher fraction of retained austenite is obtained in a globular form. The grains of retained austenite after deformation are smaller, and thus possess higher mechanical and chemical stability.

\section{EXPERIMENTAL}

For the experimental program, a low alloyed TRIP steel was chosen (Tab.1.). It is a low-cost steel, whose main alloying elements play an important role in controlling the transformation processes and stabilizing retained austenite.

The treatment schedule was simulated in a thermomechanical simulator with precise temperature and deformation control. The microstructures were examined using various metallographic methods. An appropriate etching method highlighting ferrite and retained austenite in the microstructure had to be devised. The microstructure was revealed by Nital etching, by two step etching using Nital + $\mathrm{Na}_{2} \mathrm{~S}_{2} \mathrm{O}_{5}$ water solution and by KLEMM etching colouring the retained austenite. The volume fraction of retained austenite was determined by X-ray diffraction.

The experimental program was divided into two parts. In the first part, the influence of 20-step deformation in various temperature intervals was investigated (Tab. 2). In the second, the influence of the cumulative amount of deformation on structure refinement was explored (Tab. 3).

\subsection{Influence of 20 step deformation within various temperature intervals}

At this stage, a suitable temperature window for deformation was sought. Austenitization at $900^{\circ} \mathrm{C}$ with the hold of 20 s was followed by 20 step deformation with $\varphi=2.8$ across various temperature intervals. The temperature interval was chosen to cover both intercritical and lower temperature regions.

\begin{tabular}{|c|c|c|c|c|c|c|c|c|}
\hline $\mathrm{C}$ & $\mathrm{Mn}$ & $\mathrm{Si}$ & $\mathrm{P}$ & $\mathrm{S}$ & $\mathrm{Cr}$ & $\mathrm{Ni}$ & $\mathrm{Cu}$ & $\mathrm{Nb}$ \\
\hline 0.19 & 1.45 & 1.9 & 0.02 & 0.07 & 0.07 & 0.03 & 0.04 & 0.003 \\
\hline
\end{tabular}

Tab. 1. Chemical composition C-Mn-Si [wt. \%]

\begin{tabular}{|c|c|c|c|c|c|}
\hline $\begin{array}{l}\text { Deformation } \\
\text { interval }\left[{ }^{\circ} \mathrm{C}\right]\end{array}$ & $\begin{array}{c}\text { Number } \\
\text { of def. steps } \\
/ \varphi[-]\end{array}$ & $\begin{array}{l}\text { Size of ferrite } \\
\text { grain }[\mu \mathrm{m}]\end{array}$ & $\begin{array}{c}\text { Ferrite } \\
{[\%]}\end{array}$ & $\begin{array}{l}\text { RA } \\
{[\%]}\end{array}$ & HV10 \\
\hline $900-720$ & \multirow{7}{*}{$20 / 2.8$} & $2.3 \pm 1$ & 51 & 15 & 241 \\
\hline $900-650$ & & $2.3 \pm 1.2$ & 64 & 5 & 256 \\
\hline $900-600$ & & $2.6 \pm 1.1$ & - & - & 256 \\
\hline $850-650$ & & $2.5 \pm 1.2$ & - & - & 259 \\
\hline $850-600$ & & $2.2 \pm 1.1$ & - & - & 263 \\
\hline $850-720$ & & $2.4 \pm 1.2$ & 52 & - & 247 \\
\hline $800-600$ & & $2.5 \pm 1.2$ & - & - & 266 \\
\hline
\end{tabular}

Tab. 2. Effect of 20-step deformation within various temperature intervals 


\begin{tabular}{|c|c|c|c|c|c|}
\hline $\begin{array}{c}\text { Deformation } \\
\text { interval }\left[{ }^{\circ} \mathrm{C}\right]\end{array}$ & $\begin{array}{c}\text { Number } \\
\text { of def. steps } \\
/ \varphi[-]\end{array}$ & $\begin{array}{c}\text { Size } \\
\text { of ferrite } \\
\text { grain }[\mu \mathrm{m}]\end{array}$ & $\begin{array}{c}\text { Ferrite } \\
{[\%]}\end{array}$ & $\begin{array}{c}\text { RA } \\
{[\%]}\end{array}$ & HV10 \\
\hline \multirow{3}{*}{$900-720$} & $20 / 2.8$ & $2.3 \pm 1$ & 51 & 15 & 241 \\
\cline { 2 - 6 } & $40 / 5.8$ & $2.1 \pm 0.9$ & 55 & - & - \\
\cline { 2 - 6 } & $40 / 10.4$ & $2.1 \pm 0.9$ & 60 & 10 & 245 \\
\cline { 2 - 7 } & $60 / 13.4$ & $2.1 \pm 1.1$ & 59 & 20 & 239 \\
\cline { 2 - 6 } & $60 / 15.8$ & \multicolumn{5}{|c|}{ Specimen destruction } \\
\hline
\end{tabular}

Tab. 3. Influence of different true strain amount on structure development

After deformation within the temperature interval between 900 and $720^{\circ} \mathrm{C}$, fine ferrite-bainite structure with $15 \%$ of retained austenite was obtained (Fig. 1). The tensile strength reached $832 \mathrm{MPa}$ with $\mathrm{A}_{5 \mathrm{~mm}}$ ductility of over $32 \%$. Expanding the temperature interval for deformation from $900^{\circ} \mathrm{C}$ down to 650 and $600^{\circ} \mathrm{C}$ caused pearlite to form in the structure. Pearlite is an undesirable phase in the TRIP steel microstructure, as it reduces the content of carbon in retained austenite, thus inhibiting its stabilization. The shift of the last deformation step down to $650^{\circ} \mathrm{C}$ led to stabilization of only $5 \%$ retained austenite (Tab. 2).

In other schedules, the temperature of the first reduction was decreased to $850^{\circ} \mathrm{C}$ in order to explore the influence of deformation applied in the intercritical region. Three temperature intervals of deformation were tested under these conditions (Tab. 2). When the last deformation step was shifted to $650^{\circ} \mathrm{C}$ or $600^{\circ} \mathrm{C}$, pearlite formed, as in the previous cases. After the deformation interval of $850^{\circ} \mathrm{C}-720^{\circ} \mathrm{C}$, very fine ferrite-bainite structure with a high ferrite volume fraction and fine ferritic grain was obtained again.

In the last variant with deformation temperature from $800^{\circ} \mathrm{C}$ to $600^{\circ} \mathrm{C}$, the impact of incremental deformation in the intercritical region and below was studied. A ferrite-pearlite structure with minimum volume fraction of bainite was obtained.

As evidenced by the experimental results, the temperature interval from 900 to $720^{\circ} \mathrm{C}$ appears to be the most suitable choice for deformation. Deformation applied in this temperature range promotes formation of the desirable volume fractions of ferrite and bainite and also prevents pearlite from forming.

\subsection{Influence of accumulated deformation on microstructure development}

The magnitude and intensity of deformation have substantial influence on resulting distribution and morphology of phases in TRIP steels. In this experiment, deformation was applied between 900 and $720^{\circ} \mathrm{C}$. First, forty step deformation was applied with two different magnitudes of deformation steps (Fig. 1). Thus, two different true strain intensities of 5.8 and 10.4 were obtained. The same single-step amount of deformation was then used for the sixty step deformation (Tab. 3).

The schedule with 40 step deformation and smaller deformation steps with the final true strain of $\varphi=5.8$ produced very fine ferrite-bainite structure with $55 \%$ ferrite and $9 \%$ retained austenite. The ferrite grain size of $2.1 \pm 0.9 \mu \mathrm{m}$ approaches the known physical limit of grain size achievable by thermomechanical treatment.

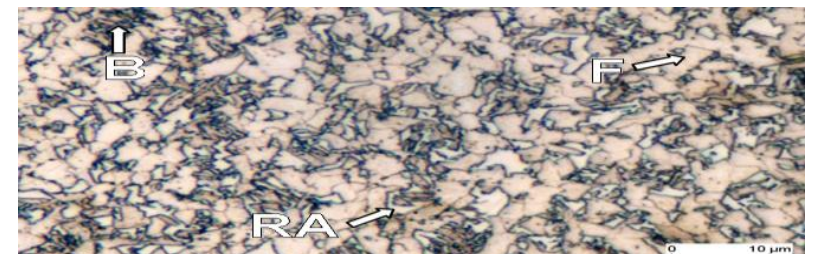

Fig. 1. 20-step deformation: $900-720^{\circ} \mathrm{C}$, two step etching (Nital $+10 \% \mathrm{Na} 2 \mathrm{~S} 2 \mathrm{O} 5$ water solution)

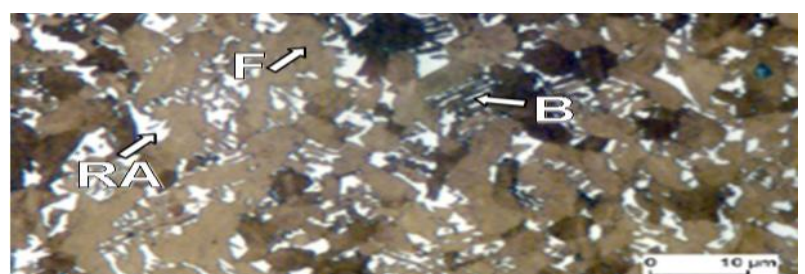

Fig. 2. 60-step deformation with the smaller deformation step: 900-720 ${ }^{\circ} \mathrm{C}, \mathrm{KLEMM}$

Upon 40-step deformation with larger deformation steps and final true strain of 10.4 , almost twice as high as the strain in the previous schedule, the ferrite fraction rose to $60 \%$ with the same ferrite grain size as above. The microstructure with high ferrite fraction and $10 \%$ retained austenite showed elongation of $\mathrm{A}_{5 \mathrm{~mm}}=34 \%$ and strength of $818 \mathrm{MPa}$. The fracture surface after tensile test was of ductile-type with dimple morphology. Further increase of true strain to 13.4 in sixty deformation steps brought no significant further refinement of microstructure and no further increase in ferrite volume fraction or grain refinement (Fig. 2). With another increase in true strain up to 15.8 , the material exhausted its plastic capacity and the sample failed.

\section{CONCLUSIONS}

The effects of various deformation temperature intervals and deformation intensities were investigated on low alloyed high strength TRIP steel. It was found that if deformation finished at a temperature of $720^{\circ} \mathrm{C}$ or higher, very fine ferritebainite structure with retained austenite fraction between 10 to $15 \%$ was obtained. An increase in incremental deformation intensity refined ferrite grain to $2 \mu \mathrm{m}$ and led to an increase in ferrite fraction up to $60 \%$.

Future studies will focus on description of the effect of cooling rate on microstructure development.

\section{ACKNOWLEDGEMENTS}

This paper includes results created within the project DFG ME 1457/18 - 1 - Using of TRIP steels for production of quasimassive components and project 1M06032 Research Centre of Forming Technology.

\section{REFERENCES}

Basuki, A.; Aernoudt, E. (1999). Influence of rolling of TRIP steel in the intercritical region on the stability of retained austenite, Journal of Materials Processing Technology, Vol. 89 - 90, (May 1999) 37 - 43, ISSN 0924-0136

Bleck, W. (2002). Using the TRIP effect - the dawn of a promising group of cold formable steels, Proceedings of International Conference on TRIP - Aided High Strength Ferrous Alloys, June 19-21, Belgium, ISBN 90-76019-17, De Cooman, B. C. (Ed.), pp. 13-24, GRIPS, Bad Harzburg

Godet, S.; Jacques, P. J. (2004). Thermomechanical processing of TRIP-assisted multiphase steels, Proceedings of 2nd International Conference on Thermomechanical Processing of Steels, June 15-17, Belgium, ISBN 35-140070-47, Lamberigts, M. (Ed.), pp. 341-347, Stahleisen, Dusseldorf

Jirková, H. et al. (2009). Influence of austenitization temperature and number of incremental steps on structure developemnt of TRIP-Steel, Proceedings of the 20th International DAAAM SYMPOSIUM, November 25-28, Vienna, ISBN 978-3-901509-70-4, Katalinic, B. (Ed.), pp. 1461-1462, DAAAM International Vienna, Vienna

Li, L.; Shan, T. (2011). Effect of transformation on springback for TRIP steel stamping, Advanced Materials Research, Vol. 221, (March 2011) 405-410, ISSN 1662-8985 